\title{
A narrativa histórica entre a vida e o texto: apontamentos sobre um amplo debate
}

\author{
Douglas Attila Marcelino \\ Universidade Federal Rural do Rio de Janeiro \\ Seropédica, RJ, Brasil \\ douglasattila@gmail.com
}

\begin{abstract}
RESUMO
Termos como poética, retórica e narrativa têm aparecido com certa constância nas discussôes sobre a natureza do conhecimento histórico, refletindo não apenas preocupações mais antigas acerca das especificidades da história, mas também os novos contornos do debate sobre a narrativa histórica das últimas décadas do século passado. Tendo em vista o tratamento do tema por diversos e importantes autores das humanidades, propóe-se uma releitura que destaca como as reflexôes já existentes nesse campo têm repercutido um redirecionamento mais geral das interrogaçôes teóricas sobre a disciplina, sobretudo quando a narrativa é concebida como elemento da vida humana que ultrapassa a dimensão da produçáo textual. Pensado de forma mais profunda, o debate sobre a narrativa indica como as reflexôes sobre a natureza do conhecimento histórico dificilmente podem ficar restritas ao plano estritamente epistemológico, muito menos negligenciá-lo.
\end{abstract}

Palavras-chave: epistemologia da história; narrativa; retórica; poética; hermenêutica.

\section{ABSTRACT}

Terms such as poetics, rhetoric, and narrative have been found rather frequently in discussions of the nature of historical knowledge, reflecting not only past concerns about specificities of history, but also the new contours of the discussion of historical narrative in the last decades of the 20th century. Based on the treatment of this topic by renowned humanities scholars, we propose a rereading emphasizing how the existing thoughts on this field have resulted in a broad redirection of the theoretical questions related to this discipline, especially when the narrative is conceived as an element of human life, going beyond the boundaries of text production. A deeper reflection on the discussion of narrative suggests that considerations on the nature of historical knowledge can hardly be restricted to or neglect the existence of a purely epistemological plane.

Keywords: epistemology of history; narrative; rhetoric; poetics; hermeneutics. 
Poética, retórica e narrativa são termos que têm aparecido com enorme constância nas discussôes sobre a natureza do conhecimento histórico, apesar de repercutirem preocupaçóes mais antigas, como no caso das comparaçóes de Aristóteles entre a história e a poesia (ainda que para diferenciá-las) ou da importante preleção de Wilhelm von Humboldt sobre a tarefa do historiador, de abril de $1821 .{ }^{1} \mathrm{~A}$ percepção crescente da relevância da tradição retórica grega e latina nas conformaçóes "modernas" da historiografia, geradora de um amplo leque de pesquisas sobre as apropriaçóes ou afastamentos dos preceitos retóricos clássicos que marcaram, respectivamente, o humanismo renascentista e o ideal científico do século XIX talvez tenha auxiliado na retomada do tema. ${ }^{2} \mathrm{O}$ aprimoramento das reflexóes teóricas e das pesquisas sobre historiografia, por outro lado, tem revelado como interrogaçóes acerca da dimensão narrativa do ofício já apareciam em historiadores relativamente pouco presentes na memória disciplinar, como Johann Gustav Droysen, ${ }^{3}$ discrepando assim da caracterizaçáo do Oitocentos como um século marcado apenas por uma espécie de "realismo ingênuo". Sem dúvida, trata-se de um universo temático acessado com certa recorrência, mas parece correto dizer que, a partir dos anos 1970 do século passado, o debate adquiriu dimensóes e contornos bastante específicos. Obras de autores como Michel de Certeau, Paul Veyne, Paul Ricœur, entre outras, são geralmente destacadas nesse sentido, mas há certo consenso de que Hayden White e seu livro Meta-história figuram no centro dos questionamentos mais recentes sobre a dimensão poética do ofício do historiador. ${ }^{4}$

A exposição das teses de White já foi feita inúmeras vezes por autores mais ou menos críticos de suas proposiçôes, originando uma numerosa bibliografia. Justamente por isso, partiremos apenas de alguns aspectos que consideramos importantes em Meta-história com o objetivo de ressaltar que os caminhos percorridos pelo debate sobre a narrativa histórica servem de indicativos de uma mudança mais profunda nas discussóes sobre a natureza do conhecimento histórico. Embora não tenha sido privilegiada nas análises de White, toda uma tradiçáo filosófica tem sido revalorizada para pensar como o problema da narrativa ultrapassa o plano da produção textual e remete para os fundamentos do pensamento histórico como experimentado na vida humana prática. Nesse caso, a narrativa, enquanto forma de constituição de sentido, opera náo somente ao nível do texto, mas está inscrita, de modo mais ou menos estruturado (dependendo da perspectiva adotada), nas vivências de homens que agem ou sofrem os acontecimentos a partir das experiências acumuladas e rearticuladas pela memória, dos seus desejos, afetos, intençóes e projetos de futuro. Redirecionados para o debate sobre a especificidade da história como forma de conhecimento, questionamentos dessa natureza apontam não apenas para a necessidade de ultrapassar o plano das interrogaçóes estritamente epistemológicas, mas também para a impossibilidade de negligenciá-lo.

\footnotetext{
${ }^{1}$ ARISTÓTELES. Poética. Lisboa: Fundação Calouste Gulbenkian, 2008. HUMBOLDT, Wilhelm von. Sobre a tarefa do historiador (1821). In: MARTINS, Estevão de R. A história pensada: teoria e método na historiografia europeia do século XIX. São Paulo: Contexto, 2010. p. 82-100.

${ }^{2} \mathrm{O}$ afastamento da história em relação à retórica, segundo Reinhart Koselleck, marcaria já o século XVIII, acompanhando a constituição do conceito moderno de história (indicamos o século XIX pelo aguçamento dessa tendência). Para o autor, uma profunda mudança na sempre tensa relação entre Histórica (Historik, no sentido dado por Droysen, do estudo das condiçôes de possibilidade do conhecimento histórico) e Poética também caracterizaria o período, tendo em vista as unidades fundadoras de sentido que passaram a conferir conteúdo épico às filosofias da história, invertendo o teor mais ou menos filosófico atribuído a cada uma delas desde Aristóteles. KOSELLECK, Reinhart. historia/Historia. Madri: Editorial Trotta, 2004. p. 47-59.

${ }^{3}$ BENTIVOGLIO, Julio. Apresentação. In: DROYSEN, Johann G. Manual de teoria da história. Petrópolis: Vozes, 2009. p. 17. ${ }^{4}$ A primeira edição da obra de Hayden White é de 1973. Aqui, utilizaremos a seguinte edição brasileira: WHITE, Hayden. Meta-história. A imaginação histórica no século XIX. São Paulo: Edusp, 1992. Os livros de Michel de Certeau, Paul Veyne e Paul Ricœur mencionados são, respectivamente, A escrita da história, Como se escreve a história. Foucault revoluciona a história em Tempo e narrativa.
} 
É sabido que Hayden White empregou o sistema tropológico de fundamentação poética para a análise da obra de historiadores e filósofos da história do século XIX, procurando isolar as estruturas inconscientes da imaginação histórica no período. ${ }^{5}$ Como apontou Hans Kellner, por outro lado, o sistema de análise por tropos poéticos remete, entre outros e com destaque, para Ciência nova, a grandiosa obra de Giambattista Vico. ${ }^{6} \mathrm{Na}$ sua análise dos três estágios que caracterizariam o ciclo de desenvolvimento e declínio das "naçôes", relativos à idade "divina", "heroica" e "humana", Vico estabeleceu uma interpretação centrada nas formas de expressão linguística para explicar a passagem do "primitivismo" à "civilização", argumentando pela existência de um momento inicial de evolução da mente humana em que o pensamento se conformaria de modo fundamentalmente poético. Com isso, o pensador napolitano pode encadear de forma diacrônica os protocolos de uso da linguagem disponíveis, identificando a metáfora com uma etapa específica na qual a imaginaçáo dos homens ainda estaria diretamente relacionada com a natureza, dada a inexistência, até então, de formas mais sofisticadas de expressão simbólica, como o uso de conceitos e analogias mais típicos do pensamento científico. ${ }^{7}$

A riqueza das concepçóes de Vico, sem dúvida, não pode ser resumida ao plano mais conhecido de sua teleologia, como destacou Isaiah Berlin, ${ }^{8}$ envolvendo outras consideraçôes extremamente importantes sobre os limites dos modelos racionalistas então em voga para o estudo do homem e delimitaçóes das especificidades das épocas históricas. Além de lançar as bases da distinção entre "observação externa" das ciências naturais e "autocompreensão" das humanidades, sua percepção das "naçôes" ou culturas como totalidades coerentes e singulares demarcaria o início de uma tradição que envolveria também outros pensadores fundamentais, como Herder, Burckhardt, Huizinga, Dilthey, entre muitos outros. Por outro lado, o sistema tropológico de Vico possui papel relevante nas elaboraçóes de Hayden White, que o cita diretamente, inclusive pelo pioneirismo no estabelecimento de uma continuidade entre o pensamento poético e imaginativo e o racional e científico.

Não há dúvida de que entre a obra de Vico e o estabelecimento da linguística moderna como campo de fundamental importância a partir de Ferdinand de Saussure e sua interpretação por Roman Jakobson há uma distância significativa. É também o uso dos tropos poéticos, por outro lado, que estrutura a abordagem da metáfora e da metonímia como polos do comportamento linguístico, aparecendo já nas análises de Ferdinand de Saussure sobre a língua como um sistema e lançando as bases para uma teoria geral dos signos (que ele chamaria de semiologia) em seu Curso de linguistica estrutural. ${ }^{10}$ O estudo desses dois tropos poéticos, depois retomado nas obras de Roman Jakobson, ${ }^{11}$ perpassava a obra de Saussure, autor que, como se sabe, ao privilegiar uma abordagem da língua como sistema de oposiçôes e diferenças, deslocou a análise substancialista então em voga e fundou as bases do que depois se tornaria conhecido como estruturalismo. De fato, como destacou François Dosse, a interpretação da obra de Saussure feita por Jakobson se tornou, em grande medida, a fonte principal do estruturalismo, fundamentando-se no par metáfora-metonímia como polos da linguagem humana e aparecendo em

\footnotetext{
${ }^{5}$ Ibidem.

${ }^{6}$ KELLNER, Hans. Language and historical representation. Madison: University of Wiscosin Press, 1989.

${ }^{7}$ VICO, Giambattista. Ciência nova. São Paulo: Hucitec, 2010.

${ }^{8}$ Isaiah Berlin destacou como um dos maiores infortúnios de Vico o fato de ter se tornado mais conhecido por sua tese dos ciclos de desenvolvimento das "naçóes", tida como seu "menos interessante, plausível e original ponto de vista". BERLIN, Isaiah. Vico e Herder. Brasília: UnB, 1982. p. 68. Argumentação semelhante pode ser vista em GARDNER, Patrick. Teorias da história. Lisboa: Fundação Calouste Gulbenkian, 1995. p. 11-15.

${ }^{9}$ WHITE, Hayden. Meta-história, op. cit. p. 47 (nota 13).

${ }^{10}$ SAUSSURE, Ferdinand de. Curso de linguistica estrutural. São Paulo: Cultrix, 1997. A primeira edição da obra é de 1916.

${ }^{11}$ Consultar o importante texto de Roman Jakobson, Linguistica e poética, citado por Hayden White (Meta-história, op. cit. p. 46, nota 13). JAKOBSON, Roman. Linguística e poética. In: . Linguistica e comunicação. São Paulo: Cultrix, 2005.
} 
autores extremamente influentes no século XX, como Claude Lévi-Strauss ${ }^{12}$ (que objetivava, como ele mesmo afirmou, trazer os avanços da linguística para o campo da antropologia, já que aquela primeira teria sido a única disciplina a ultrapassar a barreira das humanidades e a integrar o padrão de objetividade das ciências naturais). ${ }^{13}$ Tal fato explica por que Lévi-Strauss, Jacques Lacan e o próprio Roman Jakobson aparecem como referências importantes em Meta-história, autores certamente chaves do sucesso do estruturalismo, como se deu na França dos anos 1960 e foi logo "exportado" para os Estados Unidos. ${ }^{14}$ Com efeito, além de destacar o estudo das estruturas oníricas por Jacques Lacan, Hayden White mencionou diretamente Lévi-Strauss e Roman Jakobson como os principais expoentes do uso do sistema tropológico binário metáfora-metonímia, tendo em vista suas análises, respectivamente, da função poética da literatura e dos mitos do chamado "pensamento selvagem". 15

Ressalte-se que em Saussure a metáfora e a metonímia já correspondiam a atividades mentais de natureza distinta, espécies de polos do discurso humano, aspecto a partir do qual Jakobson estruturou o estudo da função poética da literatura. ${ }^{16}$ Toda forma de discurso, é claro, conjugaria os planos metafórico e metonímico, mas haveria sempre um campo dominante: no caso da prosa realista, pouco analisada em relação ao plano metafórico típico da "tradição poética romântica", a metonímia (que, no sistema de Jakobson, incorporava a sinédoque e a ironia) era o tropo dominante. ${ }^{17}$ Ora, para Hayden White, o discurso histórico não possui um status diferenciado da prosa literária realista, fato que ele indica, sobretudo, procurando repensar a noção de realismo conforme empregada nas obras de Ernst Gombrich e Erich Auerbach. ${ }^{18}$ Para White, a noção de realismo como apresentada nas análises de Auerbach sobre a literatura ocidental ou de Gombrich sobre as representaçóes pictóricas deveria ser reconsiderada no que se refere à relação entre o plano da representação e os elementos empíricos, já que as obras realistas não possuiriam qualquer acesso mais direto a uma estrutura referencial que se costuma chamar de realidade. ${ }^{19}$ Não precisamos retomar essa discussão, que opôs as críticas de White ao realismo que considerou ingênuo (prisioneiro de visôes do século XIX) às ideias de Carlo Ginzburg, que denunciou um suposto esvaziamento do termo pelo autor de Meta-história. ${ }^{20} \mathrm{O}$ importante aqui é que, com esse passo, White pode reavaliar as barreiras entre história e literatura, trazendo o sistema tropológico de análise poética utilizado no campo literário para o plano da imaginação histórica (agora, empregando o sistema de quatro tropos, conforme classificação feita pelos retóricos do século XVI). ${ }^{21}$ Um empreendimento não pouco ambicioso, tal como todos aqueles inseridos numa perspectiva estruturalista: não é à toa que

\footnotetext{
${ }^{12}$ DOSSE, François. História do estruturalismo: o campo do signo. Bauru: Edusc, 2007. v. 1, p. 12 ss.

${ }^{13}$ LÉVI-STRAUSS, Claude. Antropologia estrutural. Rio de Janeiro: Tempo Brasileiro, 1970. p. 47.

${ }^{14}$ Entre os autores citados por White estão também Lucien Goldmann, Roland Barthes, Michel Foucault e Jacques Derrida (este último, segundo François Dosse, que o caracteriza como "ultraestruturalista", é geralmente apontado como pós-estruturalista pelos norte-americanos). Ver, respectivamente, WHITE, Hayden. Meta-história, op. cit. p. 19 (nota 4). DOSSE, François. História do estruturalismo: o canto do cisne. Bauru: Edusc, 2007. v. 2, p. 33 ss.

${ }^{15}$ WHITE, Hayden. Meta-história, op. cit. p. 46 (nota 13).

${ }^{16}$ Para Jakobson, a poética era parte da linguística como teoria dos signos verbais que, por sua vez, faria parte da semiótica, enquanto teoria geral dos signos. Sua perspectiva pretendeu conjugar a análise linguística com a teoria literária, propondo um estudo da literatura (enquanto forma específica de linguagem verbal) a partir da função poética da linguagem, ou seja, a função da linguagem enquanto dirigida ao próprio signo e não ao significado (função de comunicação). JAKOBSON, Roman. Linguística e poética, op. cit. BARTHES, Roland. Elementos de semiologia. São Paulo: Cultrix, 2007.

${ }^{17}$ Sobre a sinédoque e a ironia como formas de metonímia no sistema de Jakobson, ver WHITE, Hayden. Meta-história, op. cit. p. 46 (nota 13). Para uma análise do romance realista no século XIX, ver BARTHES, Roland. O efeito de real. In: . O rumor da língua. Lisboa: Ediçóes 70, 1984. p. 131-136.

${ }^{18}$ WHITE, Hayden. Meta-história, op. cit. p. 18 (nota 4).

${ }^{19}$ Ibidem.

${ }^{20}$ Ver, entre outros, GINZBURG, Carlo. Provas e possibilidades à margem de "Il ritorno de Martin Guerre" de Natalie Zemon Davis. In: __ A micro-história e outros ensaios. Lisboa: Difel, 1991. p. 179-202.

${ }^{21}$ WHITE, Hayden. Meta-história, op. cit. p. 46 (nota 13).
} 
podemos ver referências ao estudo da "estrutura profunda da imaginação histórica" em Meta-história, ${ }^{22}$ ecoando, em certo sentido, pretensóes como as de Claude Lévi-Strauss em sua busca pela "estrutura inconsciente do espírito humano" (aí, é claro, numa proposta ainda mais ambiciosa, que visava articular uma análise estrutural em sistemas diversos, com destaque para os casos dos sistemas de parentesco e dos mitos, visando chegar a uma espécie de chave universal do "espírito humano"). ${ }^{23}$

Não é difícil perceber o viés universalista, tipicamente kantiano, do empreendimento (não estaríamos falando, em último caso, de elementos fundamentais da própria mente humana e assim retomando o sujeito transcendental kantiano?). Esse aspecto, enfatizado pelos críticos do estruturalismo, ${ }^{24}$ entretanto, assume características singulares no caso de Hayden White, justamente pelos questionamentos às pretensóes científicas dos historiadores. Afinal, não seria paradoxal utilizar todo o arsenal da filosofia moderna para desconstruir os fundamentos modernos do conhecimento histórico? Lévi-Strauss, é bom lembrar, tinha feito o mesmo com o discurso científico de forma geral, eliminando a hierarquia geralmente estabelecida em relação ao chamado "pensamento selvagem", muitas vezes considerado irracional ou ilógico. ${ }^{25}$ Certamente, essa é uma aporia do estruturalismo como um todo, e não apenas de Hayden White, mas vale a pena indicar aqui como ela gerou críticas importantes às suas ideias, mesmo no caso de autores mais relacionados ao estudo da retórica e da teoria literária.

Hans Kellner, por exemplo, ressaltou a relaçáo entre a análise tropológica e a busca por estruturas elementares da mente humana no que diz respeito à linguagem, criticando uma supervalorizaçáo do sistema de tropos nos estudos de retórica dos anos 1970 e a falta de um questionamento mais substantivo sobre sua utilidade dentro da teoria literária. ${ }^{26}$ Para Kellner, haveria uma disputa pela busca do tropo mais fundamental, geralmente identificado na metáfora (como o "tropo dos tropos") e uma desvalorizaçáo de outros elementos da retórica. Mais do que isso: remetendo às ideias de Vico, o autor procurou destacar a existência de uma "narratividade" própria ao uso do sistema de quatro tropos, que aponta para a já mencionada teoria acerca do desenvolvimento linguístico da mente humana. Assim, os sentidos produzidos pelo homem ao longo da história são submetidos a um sistema de linguagem que funciona por etapas, numa perspectiva de fundamento teleológico que encadeia de forma progressiva o curso dos protocolos linguísticos disponíveis, desde a metáfora, passando pela metonímia, pela sinédoque, até a consciência do processo alcançada com o desenvolvimento da ironia. ${ }^{27}$ Considerado nessa dimensão ampliada, portanto, o uso do sistema de classificação por tropos poéticos remeteria para toda uma teoria acerca dos estágios de desenvolvimento da mente humana, na melhor tradição de uma filosofia da história, centrada numa narrativa de fundo diacrônico não linear, mas com etapas demarcadas. É claro que White não propõe a elaboração de uma teoria da narratividade da mente humana nesses termos táo ambiciosos, mas vale a pena destacar esse aspecto dos estudos de um autor

\footnotetext{
${ }^{22}$ Idem, p. 52.

${ }^{23}$ É interessante lembrar a ironia de Fernand Braudel sobre as pretensões de Lévi-Strauss em fins dos anos 1950, quando o historiador francês lançou interrogaçôes sobre o objetivo universalista da antropologia estrutural de elaborar uma espécie de "código Morse", que passaria, até mesmo, pela cozinha, na análise dos "gostemas". BRAUDEL, Fernand. A longa duração. In: _. História e ciências sociais. Lisboa: Presença, 1972. p. 30.

${ }^{24}$ Ver as consideraçôes de Paul Ricœur publicadas em LIMA, Luiz Costa (Org.). O estruturalismo de Lévi-Strauss. Petrópolis: Vozes, 1970.

${ }^{25}$ LÉVI-STRAUSS, Claude. O pensamento selvagem. Campinas: Papirus, 2005.

${ }^{26}$ KELLNER, Hans. Language and historical representation, op. cit.

27 "My principal contention here has been that the four-trope system of renaissance rhetoric (...) also possesses an inherent narrativity. In familiar structuralist terms, these tropes are paradigmatic as figures of words, but become syntagmatic when they are inflated into figures of thought or even philosophies of history. The curriculum of mind thus becomes a diachronic course as it strives to grasp its concepts by re-rendering them in succession, metaphorically, metonymically, synecdochically, and ironically. The nature of the these successive changes seems unmediated, catastrophically sudden and discontinuous". KELLNER, Hans. Language and historical representation, op. cit. p. 250.
} 
táo importante nesse campo como Giambattista Vico, pois o viés "desconstrutivista" de alguns estudos tropológicos pode se chocar com uma visão de teor iluminista do processo histórico, ecoando na classificação progressiva dos protocolos linguísticos disponíveis aos historiadores. ${ }^{28}$

Um apontamento semelhante e agora mais crítico das concepçóes de Hayden White pode ser percebido nas obras de Dominick LaCapra. Para o historiador norte-americano, haveria uma incongruência na perspectiva de White, pois sua desconstrução do estatuto científico do discurso histórico não se afastou da mesma estrutura referencial de caráter metafísico e universalista que pretendeu criticar, conformando "a generative structuralism that presented one level of discourse (the 'tropical') as determinative in the last instance". ${ }^{29}$ Forte crítico do modelo da história social, LaCapra identificaria em White o mesmo desejo narcísico iluminista de perfectibilidade humana, de conhecimento pleno, de uma abordagem totalizante, mas não centrada no mundo sócio-histórico, e sim nas estruturas básicas da imaginação histórica. ${ }^{30}$ Assim, partindo de uma concepção "neoidealista" e "formalista" da mente do historiador, White tenderia a perceber os registros documentais que ele utiliza como uma massa "inerte", "neutra", não visualizando os textos como "redes de resistências" que impóem desafios à imaginação historiadora na sua tentativa de "reconstrução do passado". ${ }^{31}$ Não haveria lugar, então, para uma perspectiva dialógica, que buscasse compreender o passado ou os textos que nos chegam a partir do que eles indicam acerca de nossos limites, de nossas incompreensóes, enfim, naquilo que eles nos encaminham para pensar a alteridade.

Dialogando com autores como Derrida e sua desconstrução do estruturalismo, a psicanálise, Bakhtin, entre outros, a crítica de LaCapra, sem dúvida, ecoaria de forma muito mais profunda toda a tentativa de desconstrução da ontologia ocidental feita por autores como Nietzsche e Heidegger, indicando um fundamento teológico e platônico que, perpassando o essencialismo de boa parte da filosofia moderna (particularmente o projeto cartesiano e, depois, kantiano, de fundamentação da apreensão do mundo num sujeito pensante), se manifestaria mesmo naqueles que tentaram desconstruí-la, como no projeto estruturalista de forma geral. ${ }^{32}$ Concordemos ou náo com sua perspectiva, certamente ela parece menos ambígua do que propostas de corte estruturalista que procuram fundamentar uma ciência à custa da crítica aos seus fundamentos (como acontece não só com o uso do sistema tropológico por White, mas com o projeto de uma antropologia estrutural de Lévi-Strauss, igualmente relativista e universalista ao mesmo tempo: relativista do ponto de vista cultural e universalista em suas pretensóes epistemológicas).

A manifestação mais evidente dessa aporia constitutiva da proposta de Hayden White apareceria em sua visão acerca do "fato histórico", presente na ideia de "prefiguração do campo histórico" por

\footnotetext{
${ }^{28}$ A visão do desenvolvimento histórico elaborada por Vico conjugaria um caráter "teísta" com um "humanismo historicista", segundo Isaiah Berlin, pois ele seria apresentado tanto como atributo da Providência quanto do trabalho criativo e autotransformador dos homens (o autor chega a compará-la com a noção de "Artifício da Razão", de Hegel, mas indica que seria equivocado antecipar sua visão como dialética). BERLIN, Isaiah. Vico e Herder, op. cit. p. 82.

${ }^{29}$ LACAPRA, Dominick. History \& criticism. Ithaca; Londres: Cornell University Press, 1985. p. 34.

${ }^{30}$ Sobre o assunto, consultar também KRAMER, Lloyd S. Literatura, crítica e imaginação histórica: o desafio literário de Hayden White e Dominick LaCapra. In: HUNT, Lynn (Org.). A nova história cultural. São Paulo: Martins Fontes, 1992. p. 131-173.

31 "The problem of subjective relativism in White's 'poetics' of historiography stemmed a neo-idealist and formalist conception of the mind of the historian as a free shaping agent with respect to an inert, neutral documentary record (itself something like a cultural analogue of Kant's 'sensuous manifold'). This view tended to obscure both the way people in the past lived, told, and wrote 'stories' and the way the documentary record is itself always textually processed before any given historian come to it. Historians in this sense are confronted with phenomena that pose resistances to their shaping imagination and that present complex problems for their attempt to interpret and reconstruct the past". LACAPRA, Dominick. History \& criticism, op. cit. p. 35.

${ }^{32}$ Sobre as críticas de Jacques Derrida a Michel Foucault, Claude Lévi-Strauss e Jacques Lacan, ver DOSSE, François. História do estruturalismo: o canto do cisne, op. cit. v. 2, p. 33 ss.
} 
parte do historiador. ${ }^{33}$ Para além da discussão sobre o fundamento inconsciente (White utiliza noçôes como pré-cognitivo, pré-crítico e outras semelhantes) do ato poético de figuração narrativa da "realidade", que remete para o descentramento do sujeito típico do anti-humanismo estruturalista, White parece acreditar na existência de um nível de experiência histórica ainda não dotado de sentido, como se existissem fatos em estado bruto e o significado pudesse ser descolado do plano das açóes dos sujeitos históricos (para ser imputado a elas a posteriori, num gesto de figuração poética). ${ }^{34}$ Certamente, o problema aparece mais nas primeiras obras de White, mas não se restringe ao caso de Meta-história, como na conhecida polêmica com Carlo Ginzburg a propósito dos limites da representação histórica acerca do Holocausto. ${ }^{35} \mathrm{Na}$ discussão ética e epistemológica sobre a dificuldade de estabelecer uma hierarquia entre interpretaçôes mais ou menos adequadas do fenômeno (com implicaçôes, é claro, para pensar o chamado "negacionismo", já que White diria claramente que, partindo da sua perspectiva, não haveria nada na documentaçáo utilizada pelos historiadores que os encaminhasse para uma ou outra interpretação), Hayden White responderia diferenciando "proposiçôes existenciais singulares", relativas a fatos já "estabelecidos como fatos", da construção de enredo operada pelo ato de figuração poética da experiência histórica passada. ${ }^{36}$ Ora, como apontou Roger Chartier, tal proposição parece incompatível com as citaçóes de Roland Barthes presentes em seu trabalho (para quem os fatos só têm existência linguística), deixando transparecer as contradiçôes do uso de todo o arsenal crítico estruturalista conjuntamente com uma visão praticamente "positivista" de fato histórico. ${ }^{37}$

O problema não é menos importante, inclusive, porque perspectiva semelhante aparece em autores fortemente inspirados nas ideias de Hayden White, como nas propostas de Frank Ankersmit acerca de uma historiografia pós-moderna, que poria em xeque os fundamentos historicistas que, segundo ele, caracterizariam qualquer tentativa de estabelecer uma epistemologia da história. ${ }^{38}$ Defendendo o que chamou de uma "desepistemologização" da história, Ankersmit apontaria uma suposta fundamentação metafórica da perspectiva historicista para desconstruí-la a partir da noção gadameriana de "história efeitual". ${ }^{39}$ Para o autor, o discurso epistemológico, que analisa a historiografia buscando diagnosticar o desenvolvimento do pensamento histórico, se fundamentaria na pressuposição historicista de um sujeito transcendental que conseguiria se colocar externamente ao transcurso da história para visualizar

\footnotetext{
${ }^{33}$ WHITE, Hayden. Meta-história, op. cit. p. 44.

${ }^{34}$ Roger Chartier criticou esse descentramento do sujeito (no caso, do historiador) operado por White, indagando se as diferentes relaçóes que cada época histórica manteria com a retórica, inclusive no que diz respeito ao uso mais consciente dos mecanismos figurativos da linguagem, não se traduziria num maior controle das formas de construção de sentido pela narrativa. CHARTIER, Roger. Figuras retóricas e representaçôes históricas. In: À beira da falésia. A história entre certeza e inquietude. Porto Alegre: UFRGS, 2002. p. 101-116. Paul Ricœur, entretanto, tende a perceber esta como uma crítica menos relevante, que não considera a importância do empreendimento de White como um todo e a possibilidade de conceber de forma dialética essa relação entre estrutura e liberdade do historiador, ou seja, "de uma codificação que funciona ao mesmo tempo como um constrangimento e como um espaço de invenção". RICEEUR, Paul. A memória, a história, o esquecimento. Campinas: Unicamp, 2007. p. 266. Mesmo o sistema teleológico Vico, vale destacar, pressupunha um aumento do controle no uso da língua, identificando o período "humano" como aquele no qual "os homens são senhores absolutos” da linguagem. VICO, Giambattista. Apud. BERLIN, Isaiah. Vico e Herder, op. cit. p. 55.

${ }^{35}$ Existe uma enorme literatura sobre os limites da representação histórica do Holocausto, que não cabe citar aqui. $\mathrm{O}$ principal texto de White nesse plano, publicado na importante coletânea organizada por Saul Friedlander (Probing the limits of representation. Nazis and the "Final Solution"), assim como as críticas de Ginzburg, foram traduzidos e publicados em MALERBA, Jurandir (Org.). A história escrita: teoria e história da historiografia. São Paulo: Contexto, 2006.

36 WHITE, Hayden. Enredo e verdade na escrita da história. In: MALERBA, Jurandir (Org.). A história escrita, op. cit. p. 191-210.

${ }^{37}$ CHARTIER, Roger. Figuras retóricas e representaçôes históricas, op. cit.

38 ANKERSMIT, Frank. Historicismo, pós-modernismo e historiografia. In: MALERBA, Jurandir (Org.). A história escrita, op. cit. p. 95-114.

39 Sobre a noção de "história efeitual", ver GADAMER, Hans-Georg. Verdade e método: traços fundamentais de uma hermenêutica filosófica. Petrópolis: Vozes, 2008. v. 1, p. 397 ss.
} 
esse processo de forma objetiva. Daí a utilização de metáforas espaciais ser algo frequente dentro das concepçóes epistemológicas, tal como a imagem usada por Louis O. Mink de um observador que, do alto de uma colina, percebe a torrente do tempo como quem visualiza o percurso de um rio, ou mesmo as imagens presentes em expressóes como "ponto de vista", sintomáticas desse "transcendentalismo historicista” (expressão usada pelo próprio Ankersmit). A partir da perspectiva gadameriana, pela qual o passado já está presente nos homens por meio da tradição e do ato de compreensão, Ankersmit propóe a historicização do próprio observador, diagnosticando a passagem para uma condiçáo pós-moderna na qual deveríamos assumir o "ponto de vista de que nós náo temos ponto de vista algum" ${ }^{40}$ (apenas a presença contínua do passado no presente de forma dinâmica, que impede adotar qualquer valor absoluto ou imutável como base para o estabelecimento de uma forma de abordagem mais ou menos verdadeira). A fundamentação não apenas em Gadamer, mas também em Derrida é bastante clara, tendo em vista a ideia de um significado sempre escorregadio e dinâmico, que vai sendo reconstruído a partir das mudanças espaciais e temporais que marcariam o mundo histórico. ${ }^{41} \mathrm{O}$ curioso, entretanto, é a utilização desses autores para fundar uma "nova" historiografia pós-moderna, já que esse tipo de preocupação passa ao largo de suas verdadeiras discussôes. ${ }^{42}$

Para Ankersmit, o fim da epistemologia inviabilizaria a crença na atemporalidade do observador e, portanto, impossibilitaria a construção metafórica que pressupõe uma configuração espacial do passado, seja nas imagens mais simplificadas de uma totalidade homogênea ou nas mais complexas de uma multiplicidade dinâmica de fatores. Haveria, de fato, uma descontextualização, uma tentativa de "analisar as partes constitutivas do passado em sua independência 'democrática' e 'individualista', umas em relação às outras". ${ }^{43}$ Como resultado dessa perspectiva, portanto, teríamos "aquele esmigalhamento do passado que aos olhos dos comentaristas é o traço decisivo da escrita da história pós-moderna", na qual "a descontextualização ocupa o lugar da contextualização historicista e positivista". ${ }^{44}$ É interessante notar que Ankersmit perceberia esse "esmigalhamento" que impede uma ordenação mais essencialista do material histórico em obras de autores que, claramente, manifestaram sua aversão aos postulados de uma historiografia pós-moderna, como no caso de Carlo Ginzburg (cuja obra $O$ queijo e os vermes, por vezes apontada como pós-moderna, longe está de se furtar à busca de uma totalidade mais homogênea no passado, como no caso da cultura oral camponesa que, para o autor, esteve na base das leituras idiossincráticas das palavras sagradas que Menocchio elaborou em sua extravagante cosmogonia). ${ }^{45}$

\footnotetext{
${ }^{40}$ Ibidem, p. 100.

${ }^{41}$ Derrida elaborou a categoria "différance" para caracterizar esse deslocamento ao mesmo tempo espacial e temporal do significado. DOSSE, François. História do estruturalismo: o canto do cisne, op. cit. v. 2, p. 33 ss. DERRIDA, Jacques. Gramatologia. São Paulo: Perspectiva, 2004.

${ }^{42}$ Se tal aspecto parece claro no caso de Derrida e sua "gramatologia", também no de Gadamer suas preocupaçôes se fundamentavam, de fato, numa descrição de caráter fenomenológico do ato compreensivo, remetendo para o papel da consciência histórica na vida humana efetiva e ultrapassando, portanto, delimitaçóes fundadoras de uma historiografia renovada (o que não quer dizer, é claro, que suas reflexóes filosóficas não tivessem consequências importantes para a historiografia, mas apenas que o problema enfrentado ultrapassava qualquer conteúdo programático de uma "nova historiografia" que se queira buscar nas suas obras). Reinhart Koselleck, procurando diferenciar a "teoria da compreensão" de Gadamer da teoria da história, indicaria que a primeira teria, antes, um "estatuto histórico-ontológico", que tenderia, inclusive, a englobar a historiografia como parte de uma reflexão filosófica muito mais ampla. KOSELLECK, Reinhart. L'expérience de l'histoire. Paris: Gallimard; Le Seuil, 1997. p. 193-194.

${ }^{43}$ ANKERSMIT, Frank. Historicismo, pós-modernismo e historiografia, op. cit. p. 101.

${ }^{44}$ Ibidem, p. 201.

${ }^{45}$ Ibidem, p. 101. Uma crítica à obra O queijo e os vermes é feita por um dos autores que Ankermist identifica como um dos principais modelos de historiografia pós-moderna. LACAPRA, Dominick. The cheese of the worms: the cosmos of a twentieth-century historian. In: . History \& criticism, op. cit. p. 45-69.
} 
A visualização do passado como um amontoado contingente remonta, pelo menos, às críticas de Nietzsche ao historicismo e sua crença num sentido imanente aos fatos históricos, ${ }^{46}$ mas torna-se frágil quando considera que o historiador lida com uma experiência passada anterior a qualquer forma de produção de sentido. ${ }^{47}$ Tal concepção, que ecoa na tese de White sobre a "prefiguraçáo narrativa do campo histórico", também supostamente constituído de fatos preexistentes ao ato poético de produção de sentido, parece problemática na perspectiva de um autor que dialoga com Gadamer e sua hermenêutica filosófica (pela qual, como indicamos, o passado nunca estaria fora do sujeito em sua experiência de natureza compreensiva, tornando frágil, até mesmo, qualquer separação cartesiana entre sujeito e objeto e, portanto, difícil pensar o passado como um amontoado caótico). Antes de destacarmos outras concepçôes que consideramos relevantes para pensar o problema, vale indicar que, em casos como o de White, essa perspectiva talvez não apenas indique contradições com a recorrência a autores representantes do estruturalismo linguístico, mas também se relacione com o pouco diálogo com uma tradição fundamental para a compreensão do próprio Gadamer: a hermenêutica alemã, principalmente no que se refere à obra de Dilthey e às concepçóes fenomenológicas e hermenêuticas de autores como Husserl e Heidegger. ${ }^{48}$

Com efeito, certas teses narrativistas, ao focalizarem o ato poético de construção tropológica do discurso histórico, por vezes se amparam na imagem do passado como um amontoado caótico de fatos, que caberia ao historiador organizar por meio da narrativa. Ao fazê-lo, esses autores desconsideram que não há experiência sem significado, que não existem fatos brutos e que o sentido é um elemento próprio às açôes humanas. Mais do que isso, desconsideram toda a riqueza das discussóes nesse campo formuladas por uma tradição hermenêutica, pelo menos desde Dilthey e suas elaboraçôes acerca da categoria "experiência vivida" ou "vivência" (Erlebnis), tâo fundamental à filosofia alemã do século XX.49 Antecipando algumas formulaçôes de Heidegger sobre os fundamentos existenciais da historiografia na própria historicidade do homem, ou mesmo as elaboraçôes de Gadamer sobre a estrutura hermenêutica da experiência humana, a noção de "vivência" procurou justamente se contrapor à adoção de uma concepção idealista de natureza cartesiana, amparada na ideia de um eu transcendental, em estado puro, que apreende apenas cognitivamente os objetos do mundo. ${ }^{50}$ Inserido sempre na realidade, inclusive de

\footnotetext{
${ }^{46}$ Nietzsche remeteu-se à aula inaugural de Schiller na Universidade de Jena, em maio de 1789, que assim se referiu ao trabalho do historiador: "Um após o outro, os fenômenos começam a escapar do acaso cego, da liberdade sem lei, para inserir-se harmoniosamente num todo coerente — que só existe na verdade na sua imaginação”. NIETZSCHE, Friedrich. II Consideração Intempestiva sobre a utilidade e os inconvenientes da História para a vida. In: ___ Escritos sobre história. Rio de Janeiro; São Paulo: PUC-Rio; Loyola, 2005. p. 122. Jörn Rüsen atribui a Max Weber essa visão de que o passado, em si, seria caótico, não contendo qualquer sentido, a não ser pela construção subjetiva do historiador. RÜSEN, Jörn. Razão histórica. Brasília: UnB, 2001. p. 68 e 107.

${ }_{47}$ Uso aqui a palavra sentido com significado amplo, que ultrapassa sua caracterização apenas como um ato cognitivo.

${ }^{48}$ Sobre o assunto, consultar PALMER, Richard E. Hermenêutica. Lisboa: Ediçôes 70, 2006.

${ }^{49}$ Segundo Richard Palmer, a palavra Erlebnis, como substantivo singular (advindo do verbo erleben), era praticamente inexistente no alemão antes de Dilthey, que a teria buscado na obra de Goethe e passou a utilizá-la de forma bastante específica, para designar um campo de experiência pré-reflexiva que seria objeto fundamental da filosofia alemá no século XX. PALMER, Richard. Hermenêutica, op. cit. p. 113-115. Nas traduçóes para o português, além de "experiência vivida" (fórmula utilizada na tradução do livro de Palmer), é comum encontrar Erlebnis traduzido apenas como "experiência” ou "vivência".

${ }^{50}$ Para Dilthey, esse nível elementar de experiência que constituiria a vivência não poderia ser abarcado pelas categorias lógicas das ciências naturais, assim como passaria do estágio individual para o coletivo a partir da compreensão, base hermenêutica da experiência humana no mundo: "Se experimentamos, assim, nas vivências, a realidade da vida na multiplicidade de suas referências, então, visto assim, parece ser sempre de fato somente um singular, a nossa própria vida, sobre a qual sabemos por meio do vivenciar. Ele permanece um saber sobre algo único e nenhum recurso lógico pode superar a limitaçáo contida no modo de experimentar próprio do vivenciar. Somente a compreensão suspende a característica da vivência individual, assim como confere às vivências pessoais o caráter de experiência de vida. Assim como se estende a muitos homens, a criaçôes espirituais e a sociedades, ela amplia o horizonte da vida individual e abre nas ciências humanas o caminho
} 
forma pré-reflexiva, o sujeito histórico, em Dilthey, dota o mundo de significado por meio não apenas da cognição, mas também do afeto e da vontade. Ou melhor, ele já está inserido na realidade, que se confunde com sua própria vivência. ${ }^{51}$ Essa concepção de Dilthey, como destacado, seria retomada, numa perspectiva mais kantiana e fenomenológica, na noção de "mundo da vida" de Husserl, e fundamentaria as formulaçóes de Heidegger e Gadamer, conformando uma importante tradiçáo que não pode ser desconsiderada quando discutido o problema da narrativa e indicando o equívoco da crença num ato de figuraçáo poética por parte de um sujeito colocado fora da estrutura de sua vivência. ${ }^{52}$

Vários autores que dialogam com essa tradição hermenêutica e fenomenológica têm apresentado concepções mais complexas sobre a produção de sentido como algo constante das experiências humanas em seus níveis mais elementares. Se tomarmos apenas aqueles que trataram diretamente do problema da narrativa, podemos destacar Paul Ricœur, em Tempo e narrativa, que ressaltou uma "pré-compreensão" inscrita nas próprias ações dos sujeitos históricos, ou seja, a existência de uma "quase narrativa" na experiência anterior ao ato poético de composição de uma intriga. ${ }^{53}$ Conjugando as elaboraçôes aristotélicas sobre esta última noção (a "intriga" como composição poética que constitui uma totalidade com início, meio e fim) com as formulaçóes de Santo Agostinho sobre a estrutura tríplice do tempo da alma (as mediaçóes entre passado, presente e futuro), Ricœur repensou a relaçáo entre tempo e narrativa, pela qual esta última aparece como componente antropológico fundamental da vida humana, enraizando-se na própria carga subjetiva com que os homens dotam de significado suas açôes (a partir de seus desejos, intençôes, temores etc.). "Síntese do heterogêneo", que articula eventos, causas, acasos, intençóes, entre outros, a narrativa produziria uma mediação entre o tempo vivido e o tempo cosmológico, permitindo dar sentido humano ao transcurso do tempo e contendo, portanto, um fundamento existencial relacionado à própria condição histórica do homem. Assim, ela estaria enraizada na historicidade mesma da vida humana e, justamente por isso, também não poderia ser desconectada das formas pré-compreensivas das práticas sociais, existindo de modo implícito nas ações dos sujeitos históricos. Não é preciso destacar a semelhança deste tipo de perspectiva com a de outros autores que, embora sem tratar do problema da narrativa, igualmente se preocuparam com uma análise semântica das práticas sociais, reivindicando a compreensão hermenêutica que embasa a metáfora do estudo das açôes humanas como textos. ${ }^{54}$

que conduz ao universal por meio do comum." DILTHEY, Wilhelm. A construção do mundo histórico nas ciências humanas. São Paulo: Unesp, 2010. p. 102 (grifos meus).

${ }^{51}$ Como apontou Maria Nazaré Amaral, para Dilthey, não faria sentido se interrogar sobre a existência de uma realidade exterior ao sujeito. AMARAL, Maria Nazaré de C. P. Dilthey: um conceito de vida e uma pedagogia. São Paulo: Perspectiva, 1987. ___. Dilthey: conceito de vivência e os limites da compreensão nas ciências do espírito. Trans/Form/ Ação, Marília, v. 27, p. 51-73, 2004. Hans U. Gumbrecht, dialogando com a filosofia heideggeriana, tem se voltado contra a redução dos estudos humanísticos aos elementos dotados de significação e propóe uma abordagem que, sem desconsiderar a produção de sentido, se fundamenta nos fenômenos de presença, compreendidos como aquilo que opera sobre o sujeito anteriormente a qualquer apreensão significante. Seria interessante confrontar a noção de presença com esse nível elementar de vivência destacado por Dilthey, que se relaciona com qualquer "impulso" que os objetos ou outros homens produzem sobre o sujeito que compreende: "Não há homem algum, nem coisa alguma que possa funcionar apenas como objeto para mim e não contenha em si uma pressão ou um fomento, a meta de uma aspiração ou o cerceamento da vontade, uma importância, uma exigência de consideração e uma proximidade interior ou uma resistência, uma distância e uma estranheza. A concernência vital, seja ela restrita a um momento dado, seja ela duradoura, transforma esses homens e esses objetos para mim em portadores de felicidade, em ampliação de minha existência, em elevaçáo de minha força ou, então, eles restringem nesse interesse o campo de jogo de minha existência, exercendo uma pressáo sobre mim e diminuindo a minha força”. DILTHEY, Wilhelm. A construção do mundo histórico nas ciências humanas, op. cit. p. 90 (grifos meus). GUMBRECHT, H. U. Produção de presença. Rio de Janeiro: Contraponto; PUC-Rio, 2010.

${ }^{52}$ Sobre noção de "mundo da vida” em Husserl, ver os textos de Alfred Schutz em WAGNER, Helmut (Org.). Fenomenologia e relaçôes sociais: textos escolhidos de Alfred Schutz. Rio de Janeiro: Zahar, 1979.

${ }^{53}$ RICCEUR, Paul. Tempo e narrativa. São Paulo: Martins Fontes, 2010/2011. 3 v.

${ }^{54}$ Clifford Geertz talvez seja o nome mais lembrado nesse caso, mas vários autores têm dialogado com as bases 
Outros autores recentes, que também dialogam com as tradiçôes fenomenológica e hermenêutica, têm assumido concepçôes que não apenas se confrontam com os estudos tropológicos, mas consideram a estruturação narrativa como algo inerente à própria experiência humana pré-reflexiva e, portanto, anterior a qualquer pensamento sobre o passado (em Ricœur, vale destacar, o ato de composição narrativa constitui justamente a forma com que o homem, primeiramente, pensa o passado, dando sentido humano à temporalidade). É o caso de David Carr, ${ }^{55}$ que buscou conjugar elementos de diferentes perspectivas fenomenológicas com as teses narrativistas do campo da teoria literária: na fenomenologia de Husserl, o autor encontrou bases para uma reflexão sobre a estrutura temporal da consciência nas experiências mais "passivas", embora tenha considerado também a dimensão da ação e o descentramento de uma filosofia do sujeito operada pela filosofia heideggeriana; já a fenomenologia do espírito absoluto de Hegel forneceria as bases para a compreensão do problema de um ponto de vista dialético que englobasse em uma totalidade o eu e o coletivo. ${ }^{56}$ Indicando que essas diferentes tradiçóes pouco consideraram acerca do problema da narrativa, Carr procurou, entáo, retomá-lo de um ponto de vista que pretendia conjugar, substantivamente, fenomenologia e narrativismo.

É nesse sentido que Carr procurou se distanciar de Paul Ricour, autor que, supostamente, teria separado narrativa e "mundo real". ${ }^{77} \mathrm{Ou}$ seja, Ricœur, apesar de indicar a existência de uma "quase narrativa" nas açóes humanas, anterior ao próprio ato de composição de uma intriga como "síntese do heterogêneo", tomaria esse nível mais elementar de experiência como uma relação descontínua com a temporalidade, em que passado, presente e futuro ainda não configuram uma totalidade de sentido. Para Carr, seria preciso redescobrir os fatores narrativos da experiência e da ação cotidiana, percebendo as narrativas históricas e ficcionais como "extensôes e configuraçóes de seus fatores primários". ${ }^{58}$ Enfim, segundo o autor, elaboraríamos uma configuração narrativa dos eventos a partir de uma estrutura de temporalidade existente na própria experiência, na qual o passado e o futuro são postos em relação com o presente nas formas de retenção e "protensão", mesmo que não nos voltemos cognitivamente para eles. Haveria uma temporalidade interna à historicidade humana, um momento em que nossa vivência e a narratividade parecem indissociavelmente imbricados.

Talvez sejam um pouco injustas as consideraçóes de Carr sobre Ricœur, inclusive por se aproximarem mais perigosamente de uma filosofia da consciência, que, durante longo período, acreditou que, por um ato puramente introspectivo, seria possível mapear a estrutura de funcionamento da consciência humana fora da sua vivência efetiva..$^{59}$ Além de considerar a rede semântica inerente às ações humanas, Paul Ricœur concebe o momento anterior à composição poético-narrativa, marcado por essa "quase narrativa" que dota de sentido a existência, como um momento apenas ideal, já que ele teria que ser compreendido dentro do "círculo hermenêutico" como um todo. Composto, além desse momento inicial de "prefiguração", também da "figuração" narrativa e da "reconfiguração" dessa elaboração poé-

fenomenológicas e hermenêuticas dos estudos de pensadores como Max Weber e Edmund Husserl para formular propostas semelhantes de abordagem. Ver, por exemplo, as concepçóes de Alfred Schutz, retomando ideias de E. Husserl e Henri Bergson, ou, mais recentemente, tentativas de mapear um campo de estudos das culturas políticas a partir da influência da sociologia compreensiva weberiana por Daniel Cefaï: WAGNER, Helmut (Org.). Fenomenologia e relaçóes sociais, op. cit.; CEFAÏ, Daniel. Expérience, culture et politique. In:___. (Dir.). Cultures politiques. Paris: PUF, 2001. p. 93-116.

${ }^{55}$ CARR, David. Time, narrative and history. Bloomington: Indiana University Press, 1986.

${ }^{56}$ A palavra "passiva" deve ser tomada no sentido de experiências menos reflexivas, já que a proposta de Carr é justamente demonstrar que, mesmo nesses casos, a consciência é "ativa” em sua estrutura de temporalidade. CARR, David. Time, narrative and history, op. cit.

${ }^{57}$ Ibidem, p. 15 ss.

${ }^{58}$ Idem. (tradução livre)

${ }^{59}$ Richard Palmer aponta esse direcionamento para uma perspectiva cada vez mais idealista e transcendental em Edmund Husserl. PALMER, Richard. Hermenêutica, op. cit. 
tica (respectivamente, "mimese 1", “mimese 2" e "mimese 3"), o círculo hermenêutico, na realidade, apenas "hipoteticamente" se iniciaria na "mimese 1", pois ela já se conformaria, sempre, como "mimese 3 " (momento da recepção ou apropriação da narrativa). ${ }^{60}$ Trata-se, portanto, apenas de uma abstração teórica, um tipo ideal nos moldes weberianos, utilizado para permitir um entendimento mais complexo desse ciclo que compóe a configuração narrativa.

A perspectiva de Ricœur é frutífera por sua aproximação da tradição filosófica hermenêutica sem deixar de lado a visualização da "operação historiográfica" em sua totalidade, já que ela não se esgota na estrutura intrinsecamente hermenêutica da vivência, aspecto fundamental para pensar as especificidades das formas de constituiçâo de sentido operadas pela narrativa histórica. ${ }^{61}$ Vários autores, incluindo o próprio Ricœur, já apontaram como fragilidade nas teses de White a redução do conhecimento histórico apenas à dimensão da composição narrativa, tornando essa, provavelmente, a crítica mais consensual dos historiadores à sua abordagem tropológica. ${ }^{62} \mathrm{O}$ problema, por outro lado, se relaciona com um debate mais profundo e fundamental, que diz respeito ao modo como o conjunto das operaçôes realizadas pelo historiador incide sobre a forma de constituição de sentido da narrativa histórica, ou seja, à necessidade de pensar a especificidade da narrativa produzida pelos historiadores a partir da tensão entre a etapa escrituraria e as outras dimensóes do ofício relativas à pesquisa e à regulação por procedimentos metodológicos. O próprio Ricœur, em $A$ memória, a história e o esquecimento, tratou do tema a partir da categoria "representância", noção complexa já presente em trabalhos anteriores, mas que é discutida de forma um tanto sumária numa obra de tamanho fôlego. ${ }^{63}$

A categoria "representância" é utilizada por Ricœur, num primeiro sentido, para propor uma reflexão que ultrapasse a epistemologia da história, propiciando uma indagação mais propriamente ontológica sobre o estatuto peculiar da representaçáo de algo (o passado) cuja única positividade ou condição histórica de existência seria a do "ter sido" (e não a de ser agora). Esse sentido da categoria, entretanto, é o que menos interessa para nossa discussão. O outro, debatido de forma muito sucinta pelo autor, envolve a noção de "representação-suplência", mencionada apenas numa nota de rodapé ${ }^{64}$ mas que se relaciona com todo o debate existente no campo da hermenêutica sobre o acréscimo de sentido gerado em qualquer produção artística ou interpretação textual (ou seja, o importante debate sobre as condiçóes de possibilidade e os limites de qualquer interpretaçáo no plano da hermenêutica, que jamais poderia pretender uma restauração do sentido original de uma obra). Vários autores do campo da teoria literária, é claro, já ressaltaram esse acréscimo de sentido como elemento fundamental da produção historiadora, mas o restringiram à dimensão narrativa dos artifícios retóricos e poéticos utilizados. Embora explore pouco o assunto, Ricœur indica que esse acréscimo de sentido deveria ser analisado tendo em consideração o conjunto dos procedimentos que caracterizam o trabalho do historiador:

É mesmo, a meu ver, com a representação historiadora que esse aumento de significação [da representaçãosuplência] chega ao seu cúmulo, precisamente por falta de intuitividade. Ora, esse acréscimo de sentido é o fruto da totalidade das operaçôes historiográficas. Deve assim ser creditado à dimensão crítica da história. A ideia

\footnotetext{
${ }^{60}$ Noçôes como recepção, na perspectiva de Ricœur, têm que ser compreendidas num sentido semelhante ao dado por Michel de Certeau à categoria "apropriaçáo", pela qual o sujeito que se depara com qualquer tipo de produção cultural nunca é apenas passivo, elaborando sempre novos significados que, inclusive, historicizam a produção de sentido. CERTEAU, Michel de. A invenção do cotidiano. Petrópolis: Vozes, 1994/1996. 2 v.

${ }^{61}$ Paul Ricœur toma a expressão "operação historiográfica” do conhecido texto de Michel de Certeau de mesmo nome.

${ }^{62}$ Além de Paul Ricœur, essa é uma crítica recorrente, que aparece em trabalhos de Roger Chartier, Carlo Ginzburg, Jörn Rüsen, entre muitos outros, o que torna desnecessária qualquer citação mais pormenorizada.

${ }^{63}$ RICCEUR, Paul. A memória, a história, o esquecimento. Campinas: Unicamp, 2007. A categoria já aparece em Tempo e narrativa, mas discutiremos aqui considerando mais estritamente o modo como é apresentada nesta obra posterior.

${ }^{64}$ Ibidem, p. 294-296 (nota 76).
} 
de representância é então a maneira menos ruim de homenagear um procedimento reconstrutivo, o único disponível a serviço da verdade em história. ${ }^{65}$

Tratado de forma um tanto alusiva nessa obra de Ricœur, o problema foi discutido de modo semelhante, mas muito mais sistemático e abrangente, por Jörn Rüsen. Sua concepção serve para ilustrar a necessidade de confrontar a faceta poética do trabalho do historiador com outras operaçôes igualmente imprescindíveis do ofício. ${ }^{66}$ Assim como nas propostas de Carr e Ricœur, suas reflexôes, de modo geral, tomam a narrativa como um problema que ultrapassa o ato de figuração poética relativo à transformação da história em texto, remetendo para as formas de constituição de sentido que fundamentam o pensamento histórico como parte integrante do "mundo da vida" (expressão que o autor tomou em Husserl), sem o qual a própria ciência da história seria impossível. Desse modo, o tema se encaminha para a discussáo da narrativa histórica enquanto fundamento da "consciência histórica", o que corresponde a dizer que a narrativa também é compreendida por Rüsen como um dado antropológico universal relativo à condição histórica do homem, que está na base das formas com que ele opera com a temporalidade, integrando passado, presente e futuro numa unidade que permite orientar suas ações e lidar com a finitude da existência.

Por certo, também na perspectiva de Rüsen o ato poético de constituição narrativa de sentido por parte do historiador jamais poderia ser visto como um gesto autônomo, que lidaria diretamente com o passado em sua "facticidade". Sempre presente nas formas de orientação do agir e do sofrer humano, o passado já se encontraria articulado como "protonarrativa" na própria "tradiçáo", permitindo aos homens organizarem suas intençôes e expectativas no fluxo do tempo. Ou seja, a imagem do passado como um amontoado de fatos contingentes, presente nas teses de alguns narrativistas, deixa de lado o fato de ele já existir sempre como algo significativo na "memória histórica", base sob a qual os historiadores constroem suas narrativas, rememorando formas de constituição histórica de sentido presentes na cultura de seu tempo. ${ }^{67}$ Inscrita nas próprias necessidades existenciais do homem para lidar com as incertezas da vida prática, orientando-se temporalmente e dissimulando a corrupçáo do tempo, a história aparece, em Rüsen, como um ato que dá continuidade ao pensamento histórico enquanto fundamento das açóes cotidianas, potencializando a racionalidade ali presente a partir de critérios que permitem controlar ou regular metodicamente um uso do passado que se tornou consciente.

Desse modo, a formação da história como campo científico, em Rüsen, pressupóe o estabelecimento de um modo particular de lidar com a temporalidade, que ultrapassa a tradição e permite a formulação de narrativas históricas nas quais passado, presente e futuro aparecem como dimensóes distintas de uma mesma unidade de sentido. Agora, percebido efetivamente como um tempo singular por meio da "consciência histórica", o passado não se reduz a um fator de orientação dos automatismos do agir contemporâneo, mas possibilita também a elaboração de "narrativas históricas" (entre elas, a própria história, cujo grau de sofisticação exigiria formas específicas de validação, compondo assim um ideal de racionalidade próprio aos procedimentos metódicos de um determinado tipo de conhecimento

\footnotetext{
${ }^{65}$ Ibidem, p. 296. (grifo meu)

${ }^{66}$ Vamos nos basear aqui, principalmente, nas ideias de Rüsen como expostas na trilogia: RÜSEN, Jörn. História viva. Brasília: UnB, 2007. ___. Reconstruçâo do passado. Brasília: UnB, 2007. Razão histórica, op. cit.

${ }^{67}$ Martin Wiklund destacou que, para Rüsen, as experiências passadas também imporiam aos historiadores determinadas formas de compreensão e interpretação: “(...) há dados pré-narrativos de sentido [Sinn-Vorgaben] no mundo da vida e no passado aos quais toda narrativa precisa estar relacionada. Estes dados de sentido podem ser relacionados aos vestígios do passado que ‘falam' conosco e que exigem interpretação (...). Quando dados históricos de sentido nos contam algo, trata-se do oposto de nossa instrumentalizaçáo do passado”. WIKLUND, Martin. Além da racionalidade instrumental: sentido histórico e racionalidade na teoria da história de Jörn Rüsen. História da historiografia, n. 1, p. 39, ago. 2008. Disponível em: <www.ichs.ufop.br/rhh/index.php/revista/index>. Acesso em: 15 jan. 2012.
} 
científico). Como totalidade organizadora das experiências e das expectativas, portanto, a história se originaria nas carências estruturais de orientação do homem, mas pressuporia um aumento do potencial de racionalidade já inscrito no pensamento histórico da vida ordinária, sem o qual se confundiria com outras formas de constituição histórica de sentido da consciência histórica. Sua especificidade enquanto forma narrativa, nesse caso, estaria relacionada justamente com procedimentos que permitiriam fundamentar e explicitar os critérios de sentido adotados pelos historiadores, já que tais critérios estão previamente articulados na memória histórica.

Nessa ótica, o problema da narrativa histórica impóe a necessidade de tornar consciente e metodicamente regulável o uso que os historiadores fazem das formas de constituição histórica de sentidos preexistentes, aspecto que não pode ser analisado desconsiderando-se os procedimentos que inspiram a pretensão da história enquanto disciplina científica. Na verdade, para Rüsen, a especificidade da narrativa produzida pelos historiadores se deve justamente ao potencial crítico conferido pelas regras metódicas relativas à pesquisa, que conformam uma estrutura de caráter formal (sem competência para criar fontes próprias de sentido), mas com capacidade de elevar a um patamar superior de racionalidade os tipos de narrativas da consciência histórica. Ou seja, os historiadores, ao mesmo tempo que recorrem a fontes narrativas preexistentes, precisam fazer um uso consciente e regulado das formas de sentido produzidas em outros campos, como a ideologia, a arte ou a religião, acrescentando um viés crítico que confere especificidade cognitiva à sua elaboração narrativa e permite que ela não se confunda com aquela produzida nesses outros planos — dotados de capacidade própria de criação de sentido, porém não regulados por procedimentos metódicos que, inclusive, impliquem na explicitaçáo dos critérios narrativos utilizados.

Seria inviável explicar em pormenores o modo como Rüsen compreende a complexa relação entre a regulaçáo metódica da pesquisa histórica e as formas de constituição histórica de sentido utilizadas pelos historiadores. Vale apenas ressaltar que, para tal, seu esforço foi, primeiramente, o de identificar os princípios de fundamentação científica da pesquisa histórica, definidos em três principais (relativos às noçóes norteadoras de experiência, significado e sentido) e sempre compreendidos a partir do modo como eles acrescentariam potencial cognitivo aos elementos racionais já presentes no pensamento histórico da vida humana prática. ${ }^{68} \mathrm{Num}$ segundo momento, seu movimento foi o de mapear o que identificou como os quatro topoi da narrativa histórica, ou seja, as principais formas de constituição de sentido da consciência histórica (a tradicional, a exemplar, a crítica e a genética). ${ }^{69}$ Entre estas, a forma "crítica" seria aquela por meio da qual operariam os princípios metódicos de cientificização antes destacados, permitindo, inclusive, a transmutação da narrativa tradicional em exemplar, ou da exemplar em genética. Assim, através dela se produziria a tensão entre princípios metódicos e formas de constituição de sentido que daria às histórias um potencial cognitivo mais elevado, uma perspectiva crítica mais abrangente, fundamental às exigências crescentes do homem por formas de orientação no tempo dotadas de critérios sofisticados de racionalidade (e fazendo, portanto, com que a história não pudesse ser confundida com formas irrefletidas de constituição histórica de sentido, como a própria tradição). ${ }^{70}$

\footnotetext{
${ }^{68}$ Consultar, sobretudo, o capítulo 3 do primeiro livro da trilogia (Razão histórica).

${ }^{69}$ Consultar, sobretudo, o capítulo 1 do terceiro livro da trilogia (Razão viva).

${ }^{70}$ Esse ponto demarca uma diferença importante entre as perspectivas de Rüsen e Gadamer, já que, para este último, a consciência histórica se confundiria sempre com a própria tradição. Segundo Rüsen: "É sabido que Gadamer opõe os resultados cognitivos da compreensão contra a racionalidade metódica da ciência da história. Não obstante, a compreensão não só pode ser pensada como processo de pesquisa, no contexto sistemático de regulaçáo pela heurística, pela crítica e pela interpretação, como também só pode ser realizada na prática”. RÜSEN, Jörn. Reconstrução do passado. Brasília: UnB, 2007. p. 138. Consultar também CALDAS, Pedro S. P. Hans-Georg Gadamer e a teoria da história. Revista de História (UFES), v. 24, p. 63, 2010.
} 
Náo cabe aqui avaliar os aspectos positivos ou negativos da perspectiva de Rüsen, traçada em linhas muito gerais, mas é importante destacar como ela aponta a esterilidade das discussóes sobre a narrativa histórica que desconsideram outras dimensôes do ofício do historiador. Mais do que isso: ela indica como um tratamento mais apurado do problema pode ser viabilizado por uma perspectiva mais ampla no campo da teoria da história, que pretenda refletir sobre os princípios de fundamentação de cada uma das operaçôes da ciência histórica, indicando o modo peculiar com que esses elementos se conjugam no complexo processo de configuração de uma obra historiográfica. Se essa é a principal pretensão da produção teórica de Rüsen, que buscou mapear a "matriz disciplinar" da ciência da história isolando princípios gerais a partir dos fundamentos do pensamento histórico (desde sua origem na vida prática, orientando o agir contemporâneo, até seu retorno a ela por meio da formação e da didática histórica), não é de pressupor que tal seja a preocupação da maioria dos autores do campo da teoria literária que discutiram a dimensão narrativa do ofício do historiador. ${ }^{71}$ As interrogaçóes sobre as diversas operações do conhecimento histórico, portanto, deram a Rüsen, no mínimo, a possibilidade de indicar caminhos para a formulação de respostas mais complexas acerca da especificidade da narrativa histórica, que tenham valor não apenas como vetor de classificação taxonômica, mas que visem permitir um controle mais substantivo dos historiadores sobre os procedimentos da própria disciplina.

Aliás, o que confere certa singularidade à perspectiva teórica de Rüsen é que sua reflexão sobre os fundamentos do conhecimento histórico na própria historicidade da vida humana é acompanhada desse teor propositivo, que tem sido razoavelmente negligenciado no campo da teoria da história. Esse caráter propositivo, que assume a forma de princípios gerais e não de normas que arriscariam tornar apenas instrumental o debate teórico, impóe pensar como as interrogaçóes sobre a história devem atravessar campos distintos, que englobam tanto uma reflexão mais hermenêutica sobre suas bases existenciais quanto uma discussão epistemológica sobre os fundamentos metódicos da disciplina. Além de Rüsen, conforme já ressaltamos, as obras de Paul Ricœur se encaminham na mesma direção, já que suas interrogaçôes sobre a narrativa e a memória impulsionam debates importantes não apenas sobre essas duas dimensôes (da epistemologia e do que ele chama de uma "hermenêutica da condição histórica"), mas acrescentam ainda uma outra, igualmente imprescindível: o componente ético do ofício do historiador, tendo em vista a importância da sua inserção nas polêmicas sobre o modo como as sociedades produzem um "trabalho de memória" e lidam com fenômenos como as "memórias sensíveis" ou o "dever de memória". ${ }^{72}$ Todos esses planos são igualmente relevantes e não podem ser negligenciados nos debates sobre os fundamentos do saber historiográfico.

Por certo, parece forçoso notar que a relevância adquirida pelo tema da história enquanto forma de narrativa aconteceu paralelamente à revalorização das reflexôes produzidas no campo da hermenêutica acerca dos fundamentos existenciais do conhecimento histórico. Seria impossível tratar essa discussão aqui com a devida complexidade, mas ela está na base náo apenas da importância assumida pelas concepçôes de autores como Paul Ricœur, Jörn Rüsen e Reinhart Koselleck atualmente, mas da retomada de toda uma tradição que, pelo menos desde a Historik de Droysen, buscou refletir sobre o que já foi

\footnotetext{
${ }^{71}$ Anthony Grafton também criticou as análises que caracterizam a historiografia apenas a partir de sua dimensão retórica, desconsiderando como a pesquisa interfere na construção de uma narrativa específica. Seu argumento, inclusive, é que o uso corrente de notas de rodapé teria demarcado a especificidade da história moderna como uma nova forma literária: "a história da nota de rodapé mostra que a forma da narrativa histórica sofreu repetidas mutações nos últimos séculos. (...) A história da pesquisa histórica e da retórica histórica, em suma, não podem ser separadas: até mesmo os esforços mais bem informados para fazê-lo distorcem os desenvolvimentos que buscam esclarecer". GRAFTON, Anthony. As origens trágicas da erudição: pequeno tratado sobre a nota de rodapé. Campinas: Papirus, 1998. p. 189.

${ }^{72}$ Ver, especialmente, o capítulo 2 do já citado A memória, a história, o esquecimento.
} 
chamado de uma "hermenêutica histórica do ser", 73 formulando interrogaçôes meta-históricas sobre as próprias condiçôes de possibilidade da ciência da história. Assim, para além das questôes metodológicas que caracterizam a "história dos conceitos", é, sem dúvida, nas implicaçôes teórico-filosóficas para pensar a historicidade da condição humana, expressas numa visão do "tempo histórico" como relação entre experiência e expectativa, que também deve ser entendida a força atual da obra de Reinhart Koselleck.

As interrogações de Koselleck sobre o tempo remetem não apenas àquelas de Santo Agostinho, mas ecoam as discussôes de Heidegger sobre as raízes da historiografia na historicidade, aspecto que o próprio autor apontou como ainda náo solucionado. ${ }^{74} \mathrm{O}$ diálogo com a filosofia hermenêutica de Gadamer, por outro lado, é também evidente, conforme se pode notar pela tentativa de estabelecer como objeto principal da teoria da história a estrutura temporal que condiciona qualquer tipo de vivência histórica, não obstante essa semelhança seja matizada pelo enorme esforço empírico de dar conta do tema na modernidade e pelas diferenças traçadas em relação à preocupação gadameriana com uma teoria mais geral da compreensão, que toma a história apenas como uma "subdvision de la compréhension de l'existence". ${ }^{75} \mathrm{O}$ papel de acessório destinado ao método, que faria com que o título Verdade e método contivesse "quelque chose de trompeur", ${ }^{76}$ assim como a tendência à redução da existência à linguagem são também elementos que afastam Koselleck e permitem a elaboração de uma proposta teórico-metodológica centrada numa semântica dos conceitos que não inviabiliza o diálogo com a história social e o compromisso com regras de validação referidas, inclusive, ao "poder de veto" das fontes documentais. $^{77}$

É num sentido semelhante que podemos compreender a revalorização das reflexôes sobre o fundo ritual do ofício do historiador, sua relação com o trabalho de luto que atravessa os ritos de enterramento ou com as práticas cívicas e outras formas de ritualização do tempo. Michel de Certeau, possivelmente ecoando as indagaçóes a respeito elaboradas por Michelet, destacou o papel da escrita da história na exorcização da morte, comparando-a com o "túmulo" e o "rito de sepultamento" ${ }^{78}$ Nesse plano, a dimensão existencial da historiografia, compreendida como forma de dissimular a morte e a corrupçáo do tempo, é o aspecto fundamental, o que explica as comparaçôes com os rituais cívicos, que também expressariam as pretensões de eternidade do homem, com seu desejo de igualar as três dimensóes do tempo descritas por Santo Agostinho (o passado, o presente e o futuro, como na onisciente presença divina)..$^{79}$ Mona Ozouf, por outro lado, analisando os rituais da Revolução Francesa, os apresentou como expressóes do desejo de parar o transcurso do tempo, de eternizar o presente e lidar com o inesperado do futuro, indicando uma tentativa de controle da temporalidade que também poderia ser aproximada àquela da própria escrita da história. ${ }^{80}$

\footnotetext{
${ }^{73}$ BENTIVOGLIO, Julio. Apresentação. In: DROYSEN, Johann G. Manual de teoria da história, op. cit. p. 20. Sobre o assunto, consultar também CALDAS, Pedro. Que significa pensar historicamente: uma interpretação da teoria da história de Johann Gustav Droysen. Tese (doutorado em história) — Programa de Pós-Graduação em História Social da Cultura, Pontifícia Universidade Católica do Rio de Janeiro, Rio de Janeiro, 2004.

${ }^{74} \mathrm{Na}$ verdade, Koselleck coloca em dúvida se uma "análise da existência” poderia dar conta das "estruturas temporais intersubjetivas da história”. KOSELLECK, Reinhart. Futuro passado: contribuição à semântica dos tempos históricos. Rio de Janeiro: Contraponto; PUC-Rio, 2006. p. 363.

${ }^{75}$ KOSELLECK, Reinhart. L'expérience de l'histoire. Paris: Gallimard; Le Seuil, 1997. p. 182.

${ }^{76}$ Ibidem, p. 193.

${ }^{77}$ KOSELLECK, Reinhart. Futuro passado, op. cit. p. 188.

${ }^{78}$ Consultar CERTEAU, Michel de. A escrita da história. Rio de Janeiro: Forense Universitária, 2002. p. 107.

${ }^{79}$ A relação entre a prática historiográfica e os rituais cívicos (inclusive, os funerais dos "grandes homens") é discutida por Fernando Catroga em vários trabalhos. Ver, especialmente, CATROGA, Fernando. Ritualizações da história. In: ; TORGAL, Luís Reis; MENDES, José Amado. História da história em Portugal (séculos XIX-XX): da historiografia à memória histórica. Lisboa: Temas \& Debates, 1998. p. 221-361.

${ }^{80}$ OZOUF, Mona. A festa sob a Revolução Francesa. In: LE GOFF, Jacques; NORA, Pierre (Orgs.). História: novos objetos. Rio de Janeiro: Francisco Alves, 1976. p. 217-231.__. La fête révolutionnaire, 1789-1799. Paris: Gallimard,
} 
Com efeito, o debate sobre as especificidades da narrativa histórica tendeu, cada vez mais, a refletir essas interrogaçóes sobre os fundamentos existenciais da historiografia, ultrapassando a agenda de questôes indicadas no importante trabalho de Hayden White. O que parece mais frutífero nas reflexôes de alguns autores anteriormente apontados, por outro lado, é que seu diálogo com as proposiçóes filosóficas sobre a história que caracterizam a tradição hermenêutica não impede considerar as regras e formas específicas de validação da disciplina histórica. Talvez ainda faltem concepçôes mais propositivas nesse plano, sempre com maior risco de promover um tratamento a-histórico, mas que podem ser relevantes se resguardada a consciência de que serão necessários uma constante reatualização e um controle intersubjetivo sobre a ambiçáo de formular regras gerais que ultrapassem o plano das diretrizes. Enfim, a complexidade das interrogaçóes atuais sobre a natureza do conhecimento histórico impede soluçôes fáceis, restritas apenas ao plano epistemológico, porém indica que não podemos rejeitar o debate metodológico e nos fincarmos apenas em consideraçôes éticas e ontológicas sobre a condição histórica do homem. Talvez não precisemos nos afundar apenas num pragmatismo epistemológico de corte positivista ou num humanismo ético que, de tão profundo, pode correr o risco do diletantismo.

$\overline{\text { 1976. Discuti algumas concepçôes sobre a relação entre a história e os rituais cívicos em MARCELINO, Douglas Attila. }}$ Os funerais como liturgias cívicas: notas sobre um campo de pesquisas. Revista Brasileira de História, v. 31, n. 61, São Paulo, 2011. 